\title{
(C) OPEN ACCESS \\ Increasing income-based inequality in suicide mortality among working-age women and men, Sweden, 1990-2007: is there a point of trend change?
}

\author{
Ayako Hiyoshi, ${ }^{1,2}$ Naoki Kondo, ${ }^{3}$ Mikael Rostila ${ }^{2,4}$
}

\begin{abstract}
- Additional material is published online only. To view please visit the journal online (http://dx.doi.org/10.1136/ jech-2018-210696).

${ }^{1}$ Clinical Epidemiology and Biostatistics, School of Medical Sciences, Örebro University, Örebro, Sweden

${ }^{2}$ Department of Public Health Sciences, Stockholm University, Stockholm, Sweden

${ }^{3}$ School of Public Health, The University of Tokyo, Bunkyo-ku, Japan

${ }^{4}$ Centre for Health Equity Studies, Stockholm University/ Karolinska Institutet, Stockholm, Sweden
\end{abstract}

\section{Correspondence to} Dr Naoki Kondo, School of Public Health, The University of Tokyo, Bunkyo-ku, Tokyo 1130033, Japan; naoki-kondo@ umin.ac.jp

$\mathrm{AH}$ and NK contributed equally and are joint first authors.

Received 27 February 2018 Revised 8 May 2018 Accepted 23 June 2018 Published Online First 18 July 2018

\begin{abstract}
Background Income inequalities have risen from the 1990 s to 2000s, following the economic recession in 1994, but little research has investigated socioeconomic inequalities in suicide mortality for working-age men and women (aged between 30 and 64 years) over the time using longitudinal data in Sweden.

Methods Using Swedish national register data between 1990 and 2007 as a series of repeated cohort studies with a 3-year follow-up (sample sizes were approximately 3.7 to 4.0 million in each year), relative and slope indices of inequality (RII and SII respectively) based on quintiles of individual disposable income were calculated and tested for temporal trends.

Results SII for the risk of suicide mortality ranged from $27.6(95 \% \mathrm{Cl} 19.5$ to 35.8$)$ to 44.5 (36.3 to 52.6$)$ in men and $5.2(0.2$ to 10.4$)$ to 16.6 (10.7 to 22.4 ) in women (per 100000 population). In men, temporal trends in suicide inequalities were stable in SII but increasing in RII by $3 \%$ each year $(p=0.002)$. In women, inequalities tended to increase in both RII and SII, especially after the late-1990s, with 10\% increment in RII per year $(p<0.001)$.

Conclusions Despite universal social security and generous welfare provision, income inequalities in suicide were considerable and have widened, especially in women. The steeper rise in women may be partially related to higher job insecurity and poorer working conditions in the female dominated public sector after the recession. To reduce health consequences following an economic crisis and widened income inequalities, additional measures may be necessary in proportion to the levels of financial vulnerability.
\end{abstract}

\section{INTRODUCTION}

Despite these deaths being potentially preventable, every year about 800000 people die worldwide as a result of suicide, and suicide is the second leading cause of death in 15-29year olds. ${ }^{1}$ In recent decades, especially since 2000, countries have developed national strategies for suicide prevention. ${ }^{2}$ Economic fluctuations are associated with mental health and suicide risk. ${ }^{2-4}$ Welfare programmes including labour market programmes have been shown to alleviate a degree of negative impact on suicide. ${ }^{5}$ Therefore, with its generous and comprehensive welfare programmes, one might consider that Sweden could buffer such adverse influences of macroeconomic downturns; however, it has encountered challenges.
When the economic recession, the worst since the 1920s, hit the country between 1990 and 1994, the rate of unemployment soared from $2 \%$ in 1990 to $9 \%$ in 1994 and stayed between $6 \%$ and $8 \%$ in 2000 s. ${ }^{6}$ Facing the need to control spending, the government implemented tax reforms and cutbacks in social services and unemployment and sickness compensation, ${ }^{7}$ resulting in sharp declines in the redistributive effects of taxes and social benefits, from $40 \%$ in $1980 \mathrm{~s} / 90$ s to $30 \%$ in $2008 .{ }^{8}$ The downsizing of social security provision continued well into the 2000s, ${ }^{9}$ resulting in Sweden experiencing a widening income gap between employed and non-employed and the largest growth in income inequality among the Organisation for Economic Co-operation and Development countries between 1985 and the late 2000s.

Widened social inequalities often contribute to widening health inequalities, as there is likely to be deterioration in work and financial conditions, access to resources and subsequently health disproportionately among individuals in socioeconomically disadvantaged positions. However, evidence on suicide inequalities has been limited by the use of self-reported and cross-sectional data, ${ }^{10}$ the lack of individual-level socioeconomic measures ${ }^{11}$ and short observation periods, ${ }^{12}$ and there has been little empirical investigation of temporal trends. The rise in income inequalities was particularly sharp in Sweden and this may have had negative impacts on those in vulnerable positions, leading to widening suicide inequalities. Therefore, we aimed to examine whether socioeconomic inequalities in suicide mortality have increased, and where the point of change is if any, using large Swedish national register data between 1990 and 2007 as a series of repeated cohort studies with 3-year follow-ups.

\section{METHODS \\ Data and sample}

Information was obtained from multiple governmental registers. To examine health disparities of people who were actively involved in the labour market, we focused on those who were aged 30-64 years between 1990 and 2007. Data from 2008 and onwards were not available. Information on demographic and socioeconomic characteristics was supplied by the Total Population Register (Swedish acronym: RTB) and the longitudinal 
integration database for health insurance and labour market studies (LISA). Information on suicide mortality was obtained from the National Death Register, which was initiated in 1961 and covers the whole of Sweden. In total, 15 annual cohorts were created from 1990 to 2004 with 3-year follow-up for each cohort. $^{13}$ The analysed sample included 1883651 men and 1836890 women in the 1990 cohort, and 2022279 men and 1970943 women in the 2004 cohort (table 1, also see the online supplementary metarial eTable 1 for details). Individuals excluded from the study due to missing data were $<4 \%$ in the 1990 cohort and $0.1 \%$ in the 2004 cohort, mostly as a result of emigration from Sweden.

\section{Measures}

All suicide deaths were identified each year using the National Death Registry, and the number of people alive was determined at 31 December every year. Data on annual individual disposable income (total income from work and social benefits minus tax) was supplied by Swedish crowns in LISA. We grouped income into quintiles for each annual cohort separately for men and women.

Suicide death was identified using the Swedish version of the International Classification of Diseases (ICD) 9 and 10 (ICD-9: 950-959, ICD-10: X60-X84). ${ }^{14}$ The number of suicide deaths was then determined according to age (5-year age groups), sex and income quintile. Suicide deaths were counted 3 years after the income was measured to minimise the influences of pre-existing health conditions that may relate to low income and the risk of poorer mental health and thus higher risk of suicide.

\section{Statistical analysis \\ Calculation of age-standardised suicide mortality rates and inequality indices}

Age-standardised suicide mortality rates were calculated for men and women separately using the Swedish population in $2000 .^{15}$ To evaluate the differences in temporal trends, absolute and relative measures were used because they may show differing trends. As the age-standardised suicide rate appeared to increase largely monotonically with declining income, the associations were summarised using relative and slope indices of inequality (RII (Pamuk) and SII, respectively). ${ }^{16}$ The strength of the indices is their ability to provide a single summary measure of health disparity, including direction and magnitude, using data from all quintiles. To calculate SII and RII, a reverse-ordered rank variable for income is created, and categories are assigned values of the cumulative midpoint of their ranges with the values ranged between 0 and 1 . For example, the lowest income quintile was assigned a score of approximately 0.9 and the second lowest was 0.7 . Age-standardised suicide mortality rate for each year was then regressed using linear regression for SII. Dividing SII by the average suicide rate provides RII. The estimate is then interpreted as differences in predicted risk between the lowest and highest of the income hierarchy for SII. RII is the percentage of SII against the average suicide mortality rate. The choice of inequality measures may influence results and interpretation. Therefore, we also conducted complementary analyses using other disparity indices of rate difference, range difference, between-group variance and absolute concentration index. ${ }^{17}$ Because these disparity measures used parameters which were aggregated, weighted and ranked by income groups, a Taylor series approximation was used to calculate standard errors.

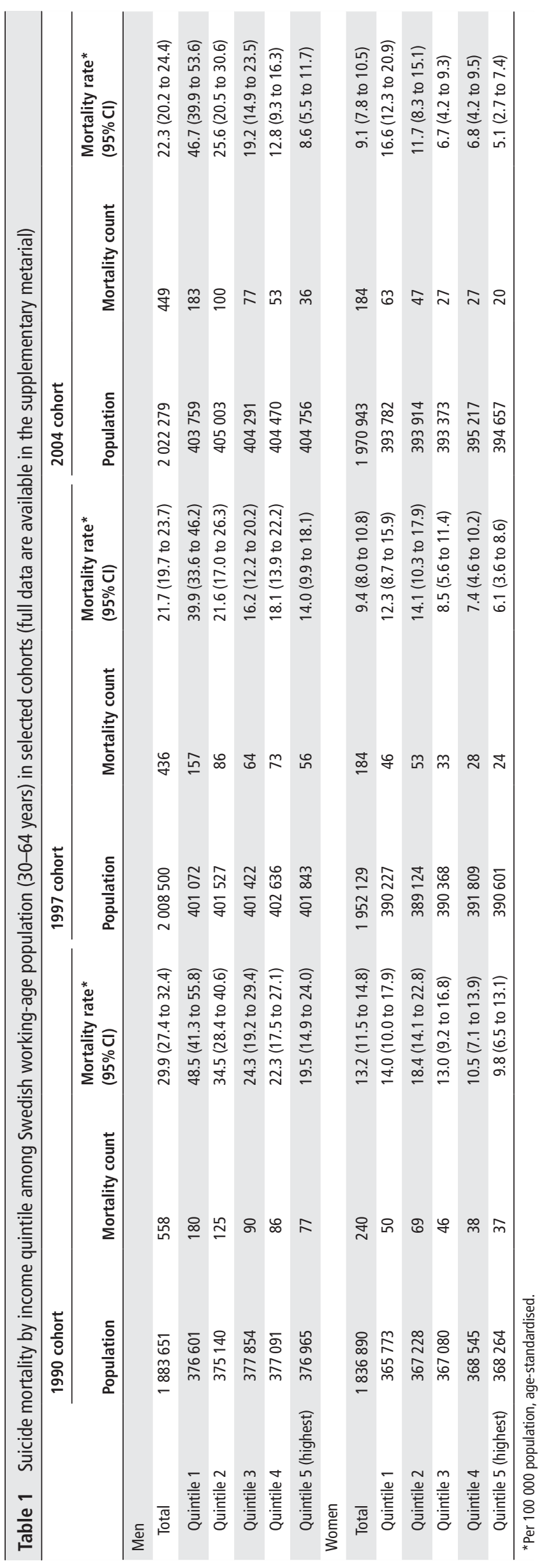




\section{Men}

60

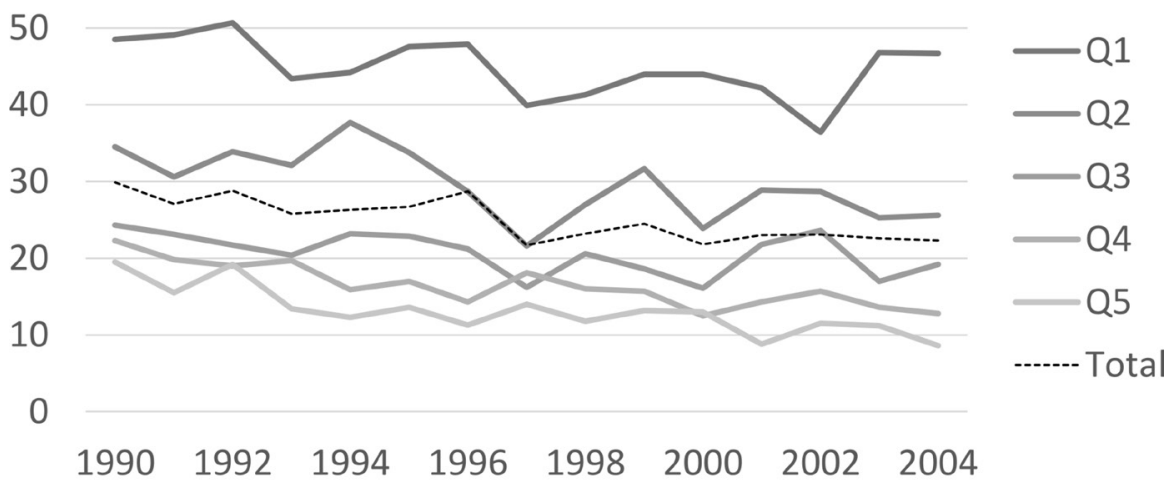

Women

60

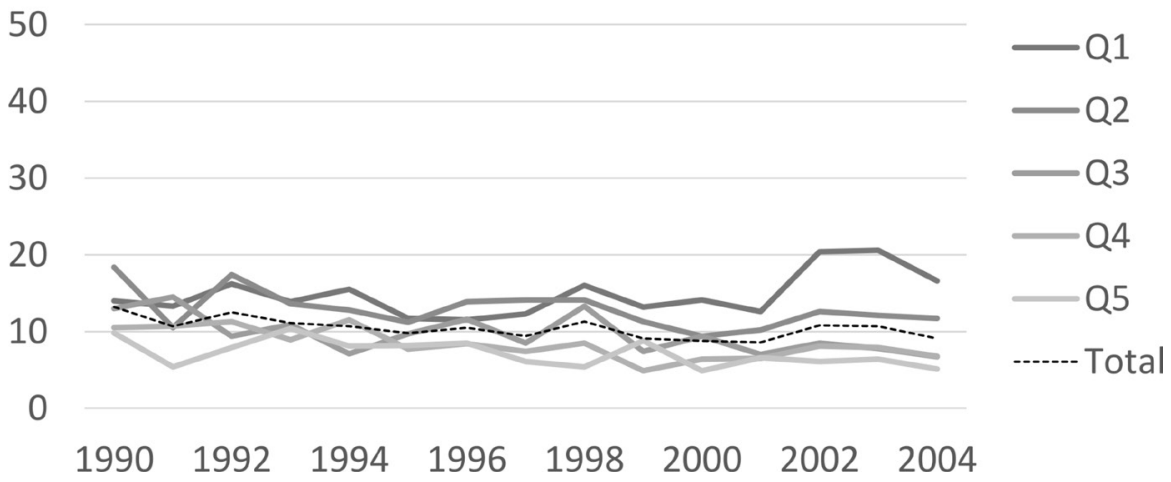

Figure 1 Age-standardised suicide mortality rates for total population and by income quintile in men and women for the 1990 to 2004 cohorts (per 100000 person-years). Q1 is the lowest income quintile and Q5 is the highest.

\section{Trend analysis}

To evaluate the changes in suicide inequality time trends, inequality measures were then analysed using the Joinpoint Regression Program. ${ }^{18}$ Joinpoint regression explores the potential points of changes in trend and tests whether having a line connecting different segments is a significantly better fit than a straight (or less segmented) line. The program uses grid search methods, creating a 'grid' of all possible locations of joinpoints and testing the sum of squared error at each point. The best fit model is the model with the minimum number of joinpoints. The number of joinpoints is determined by permutation tests, setting a significance level of each test as 0.05 . Potential autocorrelation of errors over time was also accounted for, and the regression coefficients were estimated by weighted least squares. The detailed statistical note is available elsewhere. ${ }^{19} 20$ Analyses were performed using statistical analysis package R V.3.0.3, HD*Calc V.1.2.3 and Joinpoint Regression Program V.4.0.4 (US National Cancer Institute).

\section{RESULTS}

The distribution of age-standardised suicide mortality rates for total population and income quintile for each year for men and women is presented in figure 1 (full data in the online supplementary metarial eTable 1). In general, the suicide rates were higher in men than in women and declined a little over the time. Male suicide mortality rates fluctuated over time, in the lowest two quintiles in particular, and by declining income there appeared to be stepwise increases in suicide. In women, however, income differences in the rates were less clear in the earlier period, and gradient-wise differences appeared to emerge since the late 1990s.

SII and RII for each year are presented in the online supplementary metarial eTable 2, and time trends for SIIs and RIIs are shown in figures 2 and 3. In general, SIIs and RIIs were of a much lower magnitude in women. SIIs ranged between 27.6 (95\% CI 19.5 to 35.8$)$ and 44.5 (36.3 to 52.6 ) in men and 5.2 (0.2 to 10.4 ) and 16.6 (10.7 to 22.4) in women (per 100000 population), and are interpreted as the absolute differences in rates between the (hypothetical) top and bottom of the income hierarchy while taking account for data distribution in between. SII was stable (no linear trend) over time in men $(p=0.925)$, but it showed an increasing linear trend in women, with an annual increase of $0.512(p=0.005)$, indicating the absolute differences between the (hypothetical) top and bottom income hierarchy per 100000 population widened approximately by 0.5 per year. Inequalities based on RIIs are interpreted that the mortality difference between the top and bottom of income hierarchy in relative term and were observed in men apart from in 1997. In women, RIIs tended to be negative in the 1990s and positive in the 2000s, with an association only observed in 2002. A linear increasing time trend in inequalities in suicide mortality was evident in RII in men, with annually 3.0\% increases in inequality 


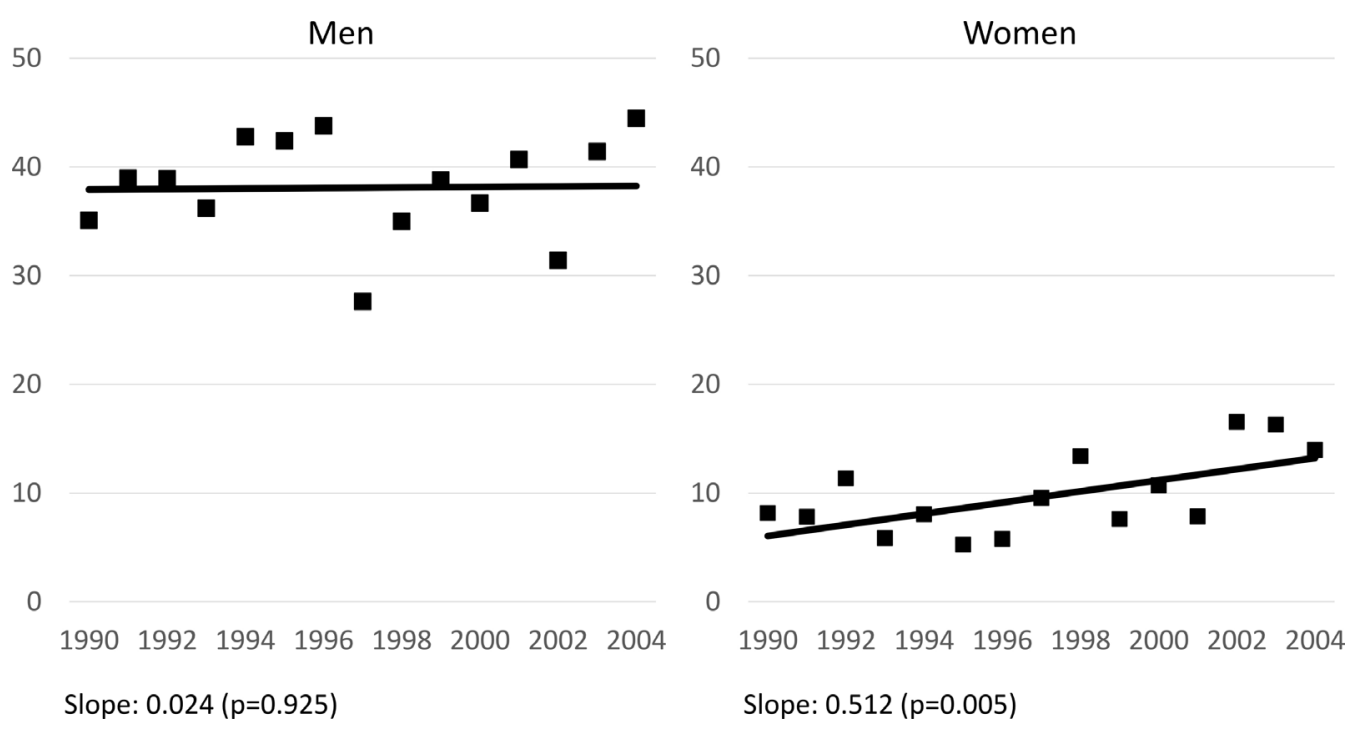

Figure 2 Trends in slope index of inequality for income in age-adjusted suicide mortality rates in men and women (per 100000 personyears). Values for slope indicate the changes in SIl per year ( $p$ value) obtained from joinpoint regression.

$(p=0.002)$. In women's RII, joinpoint regression selected a 1 -joinpoint model, indicating that there was a change in trend over time. The stable trend from the 1990 to the 1995 cohorts $(\mathrm{p}=0.613)$ was followed by an upward trend with $10.2 \%$ annual increase from the 1995 to the 2004 cohorts $(p<0.001)$ (figures 2 and 3 ).

Inequality trends were tested for alternative measures that are shown in the online supplementary metarial eTable 2 . In absolute measures, increasing linear trends were observed in women in the rate difference between quantiles one and five, the range difference and the absolute concentration index, whereas none of the indices showed a significant trend in men. All but one relative inequality measures in men, including the rate ratio, the range ratio, the index of disparity, the mean log deviation, the Theil index and the relative concentration index, showed increasing inequality trends. In women, increasing linear trends or segmented slopes of stable to increasing trends, with the change of trend from the 1995 cohort, were observed in most of the inequality measures.

\section{DISCUSSION}

The present study aimed to examine whether socioeconomic inequalities in suicide mortality have increased between 1990 and 2008 in Sweden, and if there is a point of change in the trends. We found that suicide inequalities, in relative terms, have widened, with annually a 3\% increase in men and $10 \%$ in women from the late 1990s to the late 2000s. Absolute inequalities ranged from 28 to 45 (per hundred thousand population) in men and 5 to 17 in women over the time, with stable and persisting inequalities in men but increasing inequalities in women by 0.5 each year. In western countries, although not directly comparable as age range and socioeconomic indicators were different, the absolute inequalities were on average

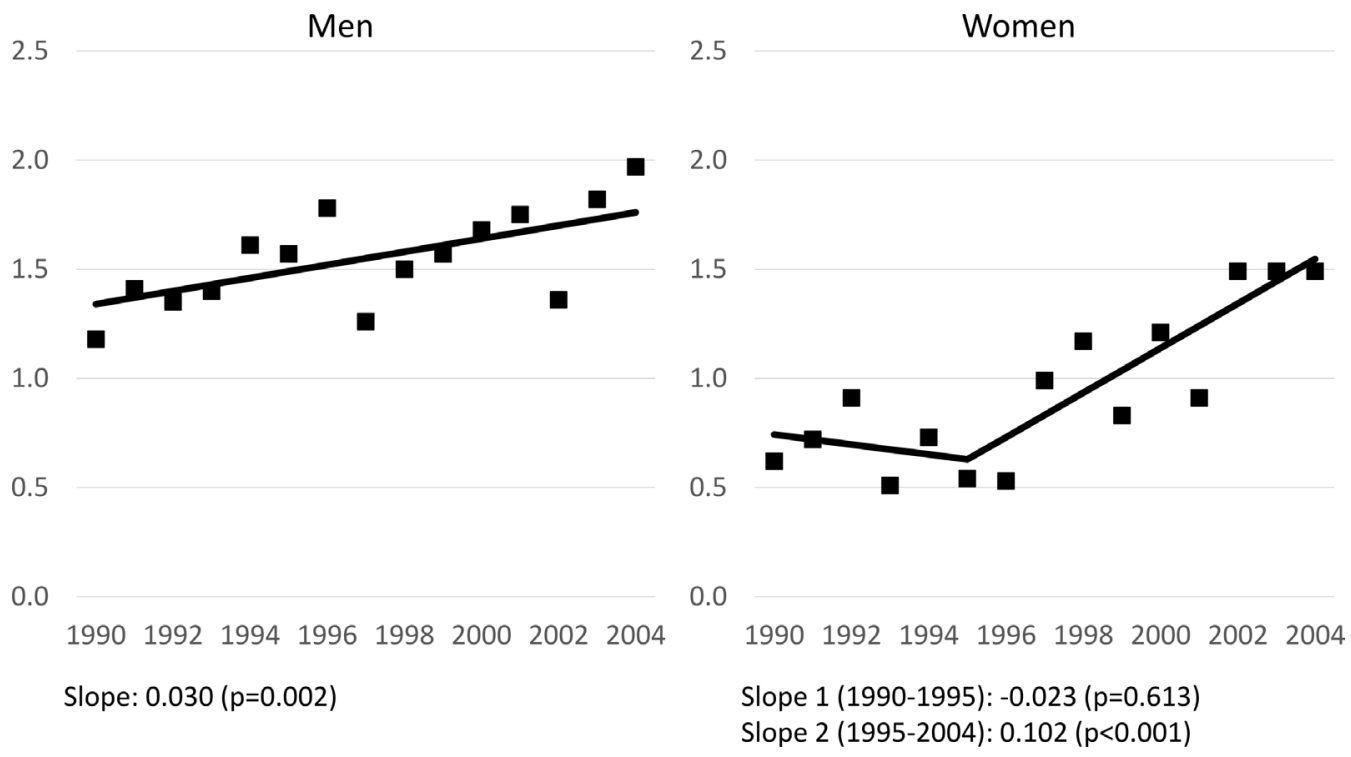

Figure 3 Trends in relative index of inequality for income in age-adjusted suicide mortality rates in men and women. Values for slope indicate the changes in RII per year ( $p$ value) obtained from joinpoint regression. In women, there was a change in time trends, from stable (1990-1995) to increasing (from 1995). 
around 15 in adult men (ranged from 2 to 40 ) and 8 in adult women (ranged from -6 to 4 ). ${ }^{11}{ }^{12}$ The gap in suicide mortality by income in Sweden, therefore, appears relatively high in magnitude. Socioeconomic inequalities in suicide have often been overlooked in formulating health policies and suicide prevention strategies. Bearing in mind that Sweden is a country with generous and universal social security and welfare provision, the substantial inequalities and the persisting and even widening trends were rather surprising.

The influence of macrosocial contexts such as income inequalities and economic recessions on mortality can vary by causes of death and socioeconomic positions. In our previous study, we assessed all-cause mortality and observed widening inequalities. ${ }^{13}$ We focused on suicide in the present study because deaths from diseases that evolve over a long time, such as cancer, are unlikely to be influenced by short-run macroeconomic fluctuations, whereas suicide appeared to be substantially affected, especially in men. ${ }^{21-23}$ In the wake of the collapse of the Soviet Union and following economic decline, Russia and some former Soviet Union countries experienced dramatic rises in mortality, in particular in men's suicide. ${ }^{2123}$ Also, after economic recessions, the rate of suicide increased in the USA ${ }^{22}$ and Japan, ${ }^{24}{ }^{25}$ with stronger negative effects on those with lower education in the USA ${ }^{22}$ but rather on those at advantageous positions in Japan. ${ }^{24}{ }^{25}$ In Sweden, suicide mortality rates appear to have reduced over time in both men and women, and the widening suicide inequalities were attributable to smaller improvement (or possibly deterioration) of the rates among poorer quintiles. Reductions of rates in men for the highest and lowest income quintiles in the 2004 cohort relative to 1990 were far greater in the highest income group $(56 \%)$ than in the lowest $(4 \%)$. In women, the mortality rates in the 2004 cohort increased by $19 \%$ in the lowest income group but decreased by $48 \%$ for the highest, compared with the 1990 cohort. However, it should be noted that the declining suicide rates may have contributed to creating increasing RIIs trends, although the increasing trend was also found in SIIs in women.

Although speculative, the possible explanations for persistent or increasing inequalities in suicide mortality may relate to the adverse influences on mental health of the economic recession, the welfare and psychiatric care reforms, changes in the composition of the population and the widened income inequalities. In Sweden, unemployment increased more drastically than in many other developed countries, ${ }^{26}$ and the high unemployment rate continued over the 1990s and even in the 2000s with some improvements. ${ }^{6}$ Unemployment, ${ }^{27}$ unaffordable housing prices and indebtedness ${ }^{28}$ and evictions ${ }^{29}$ have been associated with elevated risk of suicide death. The continued welfare downsizing in the $2000 \mathrm{~s}^{9}$ has resulted in widened income inequality, ${ }^{78}$ which may have exacerbated the sense of relative deprivation, that is, having less compared with those with higher income, among poorer groups and contributed to worsening psychosocial health. ${ }^{30}$ Also, during the economic recession, psychosocial work environments have deteriorated in various social groups, possibly due to increased demands on productivity with little investment. ${ }^{31}$ Social protection and social capital (trust) weaken during economic downturns, ${ }^{32}$ which could alleviate some of the effects of financial strain on mental health. ${ }^{33}$ Regarding the psychiatric care reforms, although the reform of shifting the care for severe mental illness from institutions to the community in 1995 has generated positive results in general, ${ }^{34}$ access to and availability of care were inadequate for some subgroups, ${ }^{34}$ which may have led such patients to be socially isolated and exacerbated suicide risk. Finally, during our study period, the proportion of people born in abroad (or both parents born in abroad) increased from $13 \%$ in 1994 to $17 \%$ in $2007,,^{35}$ and those with foreign background tended to be found with higher suicide risk. ${ }^{36}$ While we could not assess mechanisms underlying the trends, these different processes in the population, labour market, work and financial circumstances and psychosocial aspects may together have contributed to the deterioration of mental health for lower socioeconomic groups.

The difference in trends between men and women may relate to employment characteristics and the rate of suicide. In Sweden, women represent $>70 \%$ of the workforce in the public sector, ${ }^{37}$ which was directly affected by the governmental crisis-reaction measures such as privatisation and outsourcing in the latter half of the 1990s. ${ }^{38}$ Also, after employment in the public sector decreased from the early to mid-1990s, it did not recover but levelled out. ${ }^{38}$ However, while inequality trends were largely uniform across different measures in men, with stable absolute trends and increasing relative trends, trends were less consistent in women. In absolute measures, some indices showed stable trends, and, in relative measures, some indices showed segmented increment but linear in others. Thus, the change in trends should be understood with caution. Also, although suicide attempt is more frequent in women, men are overrepresented in suicide death, and the lower rates of suicide mortality in women made the relative measure tend to be more sensitive even to smaller changes. Given the descriptive and explorative nature of this study, future studies may examine the gender differences in trends and their macrosocial determinants.

Limitations of our study include the use of individual disposable income (after tax) which did not account for household information such as spousal income. Also, although own income may indicate to a great extent women's socioeconomic position ${ }^{39}$ in countries with high female labour force participation, ${ }^{40}{ }^{41}$ labour attachment has been still weaker in women, particularly for older ages in the earlier periods, which may limit comparability over time and require caution in interpretation. It may be possible that lower income was the consequence of poor health, such as psychiatric and chronic conditions, which also associate with higher suicide risk. By focusing on suicide death 3 years after the measurement of income level and excluding deaths occurring in the first 2 years of follow-up, we tried to reduce the risk of reverse causation. ${ }^{13}$ The use of uniformly and systematically collected register data which was not collected for specific research purposes may have reduced the risk of differential misclassification, ${ }^{42}$ but the level of certainty was around $80 \%$ in Swedish suicide death statistics. ${ }^{43}$ Suicide death misclassification may occur due to under-reporting as well as certification and registration procedures. The changes in autopsy rates and death ascertainment and registration procedures may have biased the estimates. ${ }^{44}$ If misclassification is assumed to be non-differential, it leads to underestimation of the association often in the most extreme exposure level, unless the likelihood of misclassification differed by income groups (differential misclassification), which may lead to overestimation or underestimation of the association. Data on other relevant confounding and explanatory factors was not available for the analysis, such as employment characteristics, marital status and lifestyle, which would improve the precision of estimates and help to understand mechanisms leading to suicide. ${ }^{13}$

The advantages of the present study are the use of a large dataset based on Swedish national registers with very little missing data for the long study period starting around the time of the economic downturn. The sample included nearly the entire Swedish working-age population. The assessment of both absolute and relative inequality time trends and different inequality measures improved 


\section{What is already known on this subject}

Economic fluctuations are associated with mental health and suicide risk. However, income inequalities in suicide mortality have been little investigated in Sweden, despite sharp increases in social inequalities in 1990s and 2000s following the economic fluctuations.

\section{What this study adds}

Suicide inequalities were substantial in Sweden, ranging from 28 to 45 (per 100000 population) in men and 5 to 17 in women. Widening suicide inequalities were found, with annual increases $3 \%$ in men and $10 \%$ in women between 1990 and 2007. Changes in the labour market, work and financial circumstances and psychosocial aspects that accompanied the economic recession and widened income inequalities may together have contributed to the deterioration of mental health for lower socioeconomic groups.

understanding of inequality trends. Income was grouped into quintiles, by which we could reflect income-based social position without adjusting for price inflation over time.

The Swedish universal welfare systems have historically produced low levels of social inequality. Yet, income inequalities in suicide mortality have been substantial in working-age men and women in Sweden. The inequalities have persisted and widened, with annually a 3\% increase in men and $10 \%$ in women from the late 1990s to 2007 . The increasing suicide risk among those with lower incomes indicates that extra measures may be recommended to mitigate these trends. Our study also highlights the importance of the monitoring of health disparities in any society, to prevent and address the unacceptable expansion of suicide inequalities.

Acknowledgements The authors thank Dr Agneta Cederström (Stockholm University) for her support for statistical analysis.

Contributors $\mathrm{AH}$ : created the first draft of the manuscript. NK: was responsible for study conception, design and analysis and critically reviewed the manuscript. MR: supported NK and AH in study conception and critically reviewed the manuscript.

Funding This work was supported by the Ministry of Education, Culture, Sports, Science and Technology, MEXT, Japan (grant number Nos. 21119002, 25253052, 18H04071 to NK); the Ministry of Health, Labour and Welfare, Japan (grant number H24-chikyukibo-ippan-009 to NK); and Swedish Research Council for Health, Working Life and Welfare (2016-07128 to MR).

\section{Competing interests None declared.}

Ethics approval Ethical permission (No. 02 - 481) was provided by the Regional Ethics Committee at Karolinska Institutet in Stockholm.

Provenance and peer review Not commissioned; externally peer reviewed.

Open access This is an open access article distributed in accordance with the Creative Commons Attribution Non Commercial (CC BY-NC 4.0) license, which permits others to distribute, remix, adapt, build upon this work non-commercially, and license their derivative works on different terms, provided the original work is properly cited, appropriate credit is given, any changes made indicated, and the use is non-commercial. See: http://creativecommons.org/licenses/by-nc/4.0/.

\section{REFERENCES}

1 World Health Organization. World health statistics 2017: monitoring health for the SDGs, Sustainable Development Goals. Geneva: World Health Organization, 2017.

2 World Health Organization. Preventing suicide: A global imperative. Geneva: World Health Organization, 2014.
3 Chang SS, Stuckler D, Yip P, et al. Impact of 2008 global economic crisis on suicide: time trend study in 54 countries. BMJ 2013;347:f5239.

4 Olfson M, Blanco C, Wall M, et al. National Trends in Suicide Attempts Among Adults in the United States. JAMA Psychiatry 2017;74:1095.

5 Stuckler D, Basu S, Suhrcke M, et al. The public health effect of economic crises and alternative policy responses in Europe: an empirical analysis. Lancet 2009;374:315-23.

6 OECD. OECD.Stat: Harmonised Unemployment rates. http://stats.oecd.org/ (accessed 23 Apr 2018).

7 Fritzell J, Hertzman JB, Bäckman O, et al. Sweden: Increasing income inequalities and changing social relations. In: Nolan B, Salverda W, Checchi D, eds. Changing Inequalities and Societal Impacts in Rich Countries. Thirty Countries' Experiences: Oxford University Press, 2014.

8 OECD. OECD Income inequality data update: Sweden, 2015.

9 Fritzell J, Lundberg 0 . Health inequalities and welfare resources: continuity and change in Sweden. Bristol: Policy Press, 2007.

10 Hong J, Knapp M, McGuire A. Income-related inequalities in the prevalence of depression and suicidal behaviour: a 10-year trend following economic crisis. World Psychiatry 2011;10:40-4.

11 Burrows S, Auger N, Roy M, et al. Socio-economic inequalities in suicide attempts and suicide mortality in Québec, Canada, 1990-2005. Public Health 2010;124:78-85.

12 Lorant V, Kunst AE, Huisman M, et al. Socio-economic inequalities in suicide: a European comparative study. Br J Psychiatry 2005;187:49-54.

13 Kondo N, Rostila M, Yngwe MÅ. Rising inequality in mortality among working-age men and women in Sweden: a national registry-based repeated cohort study, 19902007. J Epidemiol Community Health 2014;68:1145-50.

14 Rostila M, Saarela J, Kawachi I. Birth order and suicide in adulthood: evidence from Swedish population data. Am J Epidemiol 2014;179:1450-7.

15 Statistics Sweden. Population statistics. http://www.scb.se/en/finding-statistics/ statistics-by-subject-area/population/population-composition/population-statistics/ (accessed 23 Apr 2018).

16 Pamuk ER. Social-class inequality in infant mortality in England and Wales from 1921 to 1980. Eur J Popul 1988;4:1-21.

17 Harper S, Lynch J, Meersman SC, et al. An overview of methods for monitoring social disparities in cancer with an example using trends in lung cancer incidence by area-socioeconomic position and race-ethnicity, 1992-2004. Am J Epidemiol 2008;167:889-99.

18 Joinpoint, Regression Program. Version 4.0.4-May 2013, Statistical Methodology and Applications Branch, Surveillance Research Program: National Cancer Institute, 2013.

$19 \mathrm{Kim} \mathrm{HJ}$, Fay MP, Feuer EJ, et al. Permutation tests for joinpoint regression with applications to cancer rates. Stat Med 2000;19:335-51.

20 Joinpoint Regression Program. Statistical notes. https://surveillance.cancer.gov/help/ joinpoint/statistical-notes (accessed 23 Apr 2018).

21 Brainerd E. Economic reform and mortality in the former Soviet Union: A study of the suicide epidemic in the 1990s. Eur Econ Rev 2001;45:1007-19.

22 Harper S, Charters TJ, Strumpf EC, et al. Economic downturns and suicide mortality in the USA, 1980-2010: observational study. Int J Epidemiol 2015;44:956-66.

23 Men T, Brennan P, Boffetta P, et al. Russian mortality trends for 1991-2001: analysis by cause and region. BMJ 2003;327:964.

24 Wada K, Kondo N, Gilmour S, et al. Trends in cause specific mortality across occupations in Japanese men of working age during period of economic stagnation, 1980-2005: retrospective cohort study. BMJ 2012;344:e1191.

25 Kondo N, Oh J. Suicide and karoshi (death from overwork) during the recent economic crises in Japan: the impacts, mechanisms and political responses. J Epidemiol Community Health 2010;64:649-50.

26 Bergmark $\AA$, Palme J. Welfare and the unemployment crisis: Sweden in the 1990s. International Journal of Social Welfare 2003:12.

27 Garcy AM, Vågerö D. Unemployment and suicide during and after a deep recession: a longitudinal study of 3.4 million Swedish men and women. Am J Public Health 2013;103:1031-8.

28 Haw C, Hawton K, Gunnell D, et al. Economic recession and suicidal behaviour: Possible mechanisms and ameliorating factors. Int I Soc Psychiatry 2015;61:73-81.

29 Rojas Y, Stenberg SÅ. Evictions and suicide: a follow-up study of almost 22,000 Swedish households in the wake of the global financial crisis. J Epidemiol Community Health 2016;70:409-13.

30 Kondo N, Kawachi I, Subramanian SV, et al. Do social comparisons explain the association between income inequality and health?: Relative deprivation and perceived health among male and female Japanese individuals. Soc Sci Med 2008:67:982-7.

31 Rostila M. The Swedish labour market in the 1990s: the very last of the healthy jobs? Scand J Public Health 2008;36:126-34.

32 Lindström M, Giordano GN, The GGN. The 2008 financial crisis: Changes in social capital and its association with psychological wellbeing in the United Kingdom - A panel study. Soc Sci Med 2016;153:71-80.

33 Rostila M. The social capital of welfare states and its significance for population health. In: Kawachi I, Takao S, Subramanian SV, eds. Global perspectives on social capital and health. New York: Springer, 2013. 
34 Stefansson CG, Hansson L. Mental health care reform in Sweden, 1995. Acta Psychiatr Scand Supp/ 2001:82-8.

35 Sweden S. Population Statistics: Summary of Population Statistics 1960-2017. http:// www.scb.se/en/finding-statistics/statistics-by-subject-area/population/populationcomposition/population-statistics/ (accessed 24 Apr 2018).

36 Honkaniemi H, Bacchus-Hertzman J, Fritzell J, et al. Mortality by country of birth in the Nordic countries - a systematic review of the literature. BMC Public Health 2017:17:511.

37 OECD. Government at a Glance 2015. Paris 2015.

38 Anxo D, Ericson T. The effects of pay reforms and procurement strategies on wage and employment inequalities in the Swedish public sector: National report, 2012.

39 Åberg Yngwe M, Kondo N, Hägg S, et al. Relative deprivation and mortality--a longitudinal study in a Swedish population of 4.7 million, 1990-2006. BMC Public Health 2012;12:664.
40 Bartley M. Health inequality: an introduction to theories, concepts and methods. Cambridge: Polity Press, 2004

41 OECD. Labour force participation rate. https://data.oecd.org/emp/labour-forceparticipation-rate.htm (accessed $23 \mathrm{Apr}$ 2018).

42 Qin P, Agerbo E, Mortensen PB. Suicide risk in relation to socioeconomic, demographic, psychiatric, and familial factors: a national register-based study of all suicides in Denmark, 1981-1997. Am J Psychiatry 2003:160:765-72.

43 Tøllefsen IM, Helweg-Larsen K, Thiblin I, et al. Are suicide deaths under-reported? Nationwide re-evaluations of 1800 deaths in Scandinavia. BMJ Open 2015:5:e009120.

44 Kapusta ND, Tran US, Rockett IR, et al. Declining autopsy rates and suicide misclassification: a cross-national analysis of 35 countries. Arch Gen Psychiatry 2011;68:1050-7. 